\title{
КОНСТРУКТИВНО-КРИТИЧЕСКАЯ ВЕРИФИКАЦИЯ ТЕОРЕТИЧЕСКОЙ МОДЕЛИ КРУГООБОРОТА ТОВАРНОЙ ФОРМЫ РАБОЧЕЙ СИЛЫ В ПОСТСОВЕТСКИЙ ПЕРИОД СОВРЕМЕННОЙ РОССИИ'
}

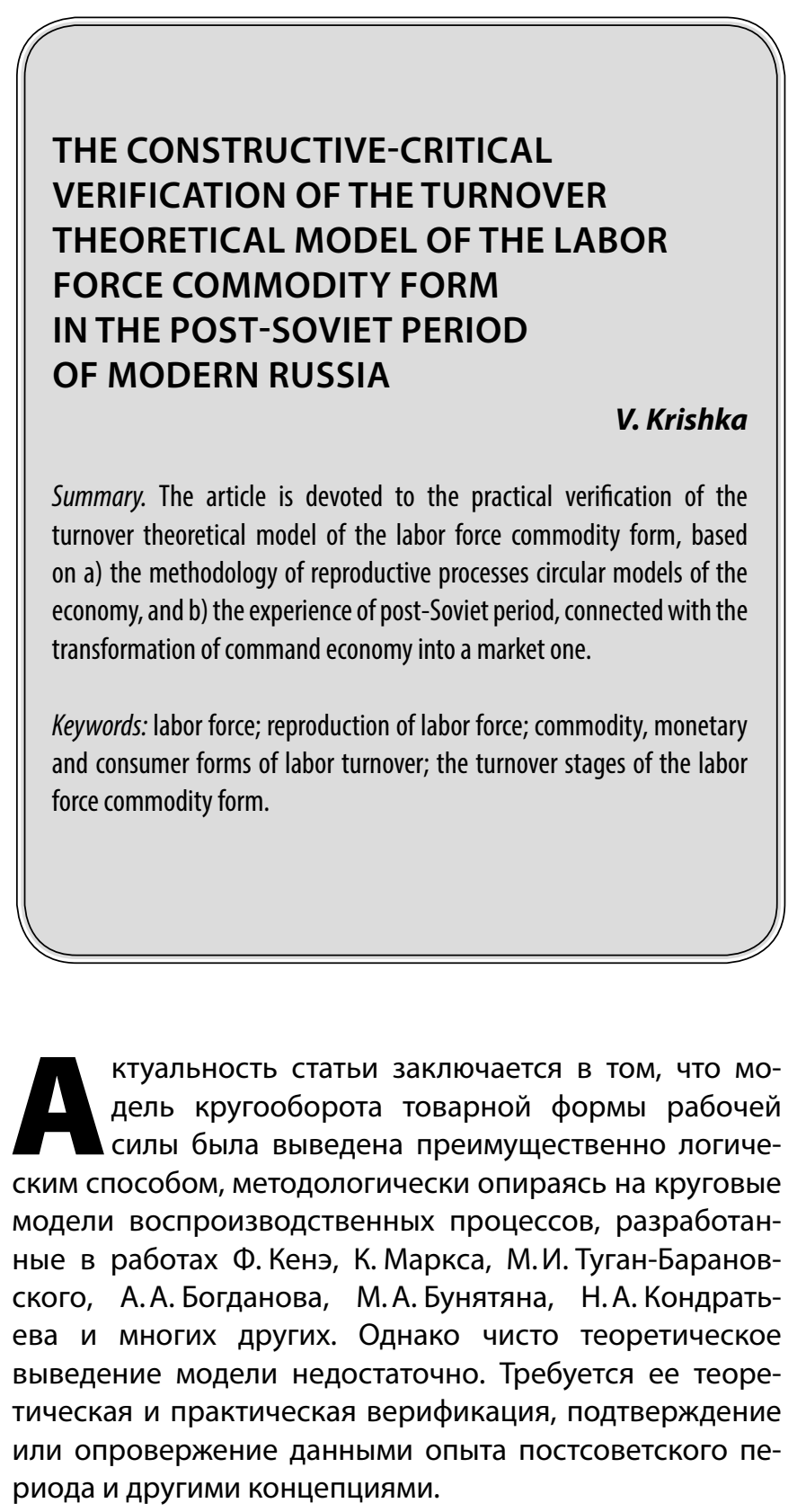

\author{
Крышка Виктор Иванович \\ К.э.н., дочент, ФГБОУ ВО «Алтайский \\ государственный университет» (Барнаул) \\ kryshka@mail.ru
}

Аннотация. Статья посвящена практической верификации теоретической модели кругооборота товарной формы рабочей силы, созданной на основе а) методологии круговых моделей воспроизводственных процессов экономики, и б) опыта постсоветского периода, связанного с трансформацией командно-административной модели экономики в рыночную.

Ключевые слова: рабочая сила; воспроизводство рабочей силы; товарная, денежная и потребительская формы кругооборота рабочей силы; стадии кругооборота товарной формы рабочей силы.

Цель статьи - это конструктивно-критическая верификация теоретической модели кругооборота товарной формы рабочей силы на основе опыта рыночных преобразований в постсоветский период и критического анализа концепций современного мейнстрима и других альтернативных концепций.

Исходя из поставленной цели, в статье решаются следующие задачи.

1. Адаптация марксистской модели кругооборота капитала в целом и его денежной, товарной и производительной форм в частности, к пробле-

${ }^{1}$ Статья подготовлена при финансовой поддержке Российского фонда фундаментальных исследований в рамках научного проекта № 19-010-00491 «Исследование взаимного влияния уровня оплаты труда и воспроизводства рабочей силы в условиях макроэкономических и институциональных изменений в российской экономике в 1992-2018 гг.». 
ме воспроизводства и кругооборота товарной формы рабочей силы.

2. Выяснение вопроса о товарном или нетоварном характере рабочей силы в постсоветский период, т.е. начальной и конечной «точек» модели кругооборота товарной формы рабочей силы.

3. Характеристика стадий кругооборота товарной формы рабочей силы.

4. Выделение, наряду с кругооборотом товарной формы рабочей силы, денежной и потребительской форм кругооборотов рабочей силы.

1. К.Маркс во втором томе «Капитала» выделил: 1) денежную (Д - T...П...T - Д'), 2) товарную $\left(\mathrm{T}^{\prime}-Д^{\prime}-T . . \Pi \ldots T^{\prime}\right)$ и 3) производительную $\left(П . . T^{\prime}-Д^{\prime}-T . . \Pi\right)$ формулы (фигуры) кругооборота капитала [1, с. 75-172]. Однако, очевидно, ввиду концентрации внимания на проблеме прибавочной стоимости, он не придал значения тому, что есть еще одна фигура кругооборота товарного капитала, $T . . П . . . T-Д^{\prime}-T$, связанная с кругооборотом товарной формы факторов производства, т.е. а) средств производства $\left(T_{C П}\right)$ и б) рабочей силы ( $\left.T_{P C}\right)$. Остановимся на этот подробнее.

Если оставить в стороне а) кругооборот средств производства, б) прибавочную стоимость, в) время производства и обращения, то формула кругооборота переменного капитала ( $V$ ) по Марксу со стороны собственников средств производства (работодателей) будет иметь такой вид:

$$
Д_{3 \Pi}-T_{P C} \ldots \Pi\left(T_{P}\right) \ldots T_{3 \Pi}-Д_{B 3 \Pi,}
$$

где $Д_{3 п}$ - денежная заработная плата, $T_{P C}-$ товар рабочая сила, ...П $\left(T_{P}\right) \ldots$ - процесс производства, включая процесс труда $\left(T_{P}\right), T_{3 \Pi}$ - товарная форма оплаты труда; Д ВзП - возмещенная из выручки заработная плата.

Со стороны наемных работников этот же кругооборот, на наш взгляд, будет выглядеть так:

$$
T_{P C}-Д_{3 \Pi \ldots} \ldots T_{P} \ldots P-Д_{3 \Pi,}
$$

где $P$ - выполненная работа, Д денежная заработная плата.

Если сравнить формулы 1 и 2, то можно выделить следующее.

Во-первых, взаимное проникновение и сопряженность указанных кругооборотов вплоть до стадии реализации товарной продукции, $T-Д$.
Во-вторых, можно выделить так называемый «внешний рынок труда», т.е. «куплю-продажу» рабочей силы, где $Д_{3 \Pi}-T_{P C}$ (купля рабочей силы) и $T_{P C}-Д_{3 \Pi}$ (продажа рабочей силы).

В-третьих, можно также выделить «внутренний рынок труда», который формируется внутри предприятий, где, на наш взгляд, возникает товар особого рода — «выполненная работа» - как совокупность трудовых актов, имеющих относительно законченный и предметный характер.

Таким образом, исходя из указанных кругооборотов, так называемый «рынок труда» в целом необходимо делить на внешний и внутренний рынки труда. На первом рынке «продается-покупается» а) «рабочая сила», на втором - б) «выполненная работа».

Если оставить в стороне формулу 1 в целом, то с позиции товарной формы рабочей силы ее собственный кругооборот, связанный с воспроизводством рабочей силы, выходит за рамки определенного выше «рынка труда» в целом и включает, на наш взгляд, акты: 1) потребительского выбора средств потребления; 2) процесс потребления купленных средств потребления; 3) удовлетворение потребностей и производство (воспроизводство) рабочей силы, или

$$
\begin{aligned}
& T_{P C}-Д_{3 \Pi \ldots} \ldots T_{P} \ldots P-Д_{Р 3 \Pi \ldots} \ldots Д_{Р С 3 \Pi}-T_{C \Pi T \ldots} . \\
& \Pi_{T \ldots} V_{\Pi}-T_{B P C}
\end{aligned}
$$

где $Д_{Р С 3 п}$-поток расходовденежной заработной платы, $T_{C П T}-$ товарная форма средств потребления; $\Pi_{T}-$ процесс потребления купленных средств; $V_{\Pi}$-удовлетворенность потребностей, $T_{B P C}-$ воспроизведенная рабочая сила.

2. Как хорошо известно, в марксистско-ленинской литературе советского периода в СССР однозначно утверждалось следующее.

При капитализме, т.е. при господстве частной гражданской собственности на средства производства, рабочая сила является товаром особого рода, специфика которого заключается в том, что потребительная стоимость рабочей силь посредством конкретного, полезного труда производит прибавочную стоимость для владельцев средств производства (капитала), а меновая стоимость рабочей сильл, или «цена труда», является превращенной формой стоимости средств существования рабочих [2, с. 210-219].

При социализме, напротив, утверждалось, что при ликвидации частной собственности на средства производства рабочая сила перестает быть товаром, поскольку сами рабочие являются сособственниками средств 
производства, хотя сохраняется видимость существования оплаты труда ввиду действия при социализме закона распределения по труду в соответствии с его качеством и количеством. В частности, парадигма отсутствия наемного труда при социализме с 1922 г. по 1991 г. выражалась в модели кругооборота средств социалистических (общенародных и коллективных) предприятий, или

$$
\text { Д- }
$$

Сравнивая две вышеприведенные доктрины и парадигмы, возникает вопрос, является ли рабочая сила товаром в современный постсоветский период? От ответа на этот вопрос зависит верифицируемость модели кругооборота товарной формы рабочей силы в постсоветский период в ее начальной и конечной «точках».

Ответ на этот вопрос заключается в следующем.

Во-первых, переходный период от командно-административной системы хозяйствования к рыночной экономике в нашей стране, как известно, знаменовался масштабным процессом приватизации основных средств производства, находившихся ранее в собственности у тотального собственника - государства. В результате процесса приватизации возникла, точнее, была возрождена плюралистическая, децентрализованная система института гражданской частной собственности на основные средства производства и средства потребления. Возникновение указанного института привело к тому, что частная гражданская собственность приобрела не только законный, но и фактический характер.

Во-вторых, в этой связи по сути дела возникла двойная форма соединения факторов производства, т.е. труда и капитала. Первая - на основе «своего» труда и «своих» средств производства, т.е. система самозанятости населения в рамках натурального и товарного типа хозяйствования. Вторая - на основе «своих» средств производства и «чужого» наемного труда, т.е. система наемной занятости населения на основе купли-продажи рабочей силы.

Таким образом, возникновение института гражданской частной собственности, в частности, на средства производства, подтверждает, верифицирует модель кругооборота товарной формы рабочей силы в ее исходной и конечной точках $\left(T_{P C}\right)$, выражающих товарнылй характер рабочей силы.

3. Исходя из модели 3, можно выделить следующие стадии, рассмотрение которых конкретизирует верификацию данной модели.
Первая стадия. $T_{P C}-Д_{3 П}$. Со стороны наемных работников, это стадия трудоустройства, заключения трудовых договоров (контрактов) по временной продаже рабочей силы, потенциального труда. Со стороны работодателей $Д_{3 П}-T_{P C}$ - это прием на работу в соответствии со сложившимися вакансиями рабочих мест. Присмотримся к этому двойному процессу продажи-купли $T_{P C}$ внимательнее.

В целом рассматриваемый здесь и сейчас «внешний рынок труда» - это особенной рынок, который имеет следующую специфику.

Во-первых, продажа рабочей силы имеет временный характер и связана с определенной продолжительностью рабочего времени. Вневременная продажа означает рабство. Рабочее время ограниченно не только законодательно, но и связано с интенсивностью труда, т.е. затратами труда в единицу рабочего времени. Так, чем выше интенсивность труда, тем быстрее наступает по учению маржиналистов предельная тягость тру$\partial a$, отрицательная полезность труда, выраженная, зачастую, в возникновении произвольных и нерегламентированных перерывов в труде и, даже, преждевременном уходе с работы.

Во-вторых, на этом рынке рабочая сила и ее реализация в процессе труда для наемного работника является средством продажи, а цүелью является получение заработной платы. Деньги на этом рынке выполняют функцию средства платежа, которая возникает тогда, когда в момент времени реализация потребительной стоимости товара, не совпадает с реализацией его меновой стоимости. Другими словами, работодатели на этом рынке вынуждены авансировать заработную плату, т.е. выполнять функцию предоплаты потенциального труда, а рабочие вынуждены авансировать свой «труд». Эта двойная форма авансирования ставит под сомнение марксистскую теорию эксплуатации и вызывает ее критику со стороны современных представителей неоавстрийской школы [3].

В-третьих, получение наемным работником авансированной суммы заработной платы, обычно в размере $40 \%$ от ее гарантированной (окладной) части, в частности, говорит о том, что работодателю необходимо предусмотреть авансирование фонда оплаты труда (ФОТ) для поддержания работоспособности наемных работников до окончания рабочего периода и получения выручки от реализации, при этом необходимо учесть то, чем больше рабочий период, тем больше должна быть величина авансированного фонда оплать труда.

В-четвертых, в современной учебной микроэкономической литературе мейнстрима эта стадия отражена 
прежде всего в виде геометрической модели кривых спроса на рабочую силу и предложения рабочей силы (потенциального труда) в связи с заработной платой. Эта модель не верифицируется данными опыта постсоветского периода, поскольку в ней нет предложения, как указывалось выше, рабочих мест.

Вторая стадия. ...П( $\left.T_{P}\right) \ldots$ - стадия проиесса производства готовой товарной продукции со стороны работодателей и стадия процесса труда, включая выполнение определенных работ со стороны наемной рабочей силы.

Процесс производства включает в целом а) естественные, б) технологические и б) трудовые процессы. Значение этих процессов меняется и зависит от отраслевого характера производства. Так, в сельском хозяйстве превалирует доля естественных, природных процессов без непосредственного участия средств производства (капитала и труда). В промышленности - капитал (средства производства). В отраслях сферы услуг основным фактором является труд. В процессе труда, с позиции цели статьи и ее задач, как уже отмечалось, можно выделить товар особого рода, т.е. «выполненную работу».

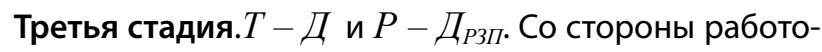
дателей - это продажа произведенного товара по окончанию рабочего периода, $T$ - Д. Со стороны рабочегоэто $P$ - Д валовой (начисленной) заработной платы $\left(Д_{H з п}\right)$, которая за вычетом налоговых платежей переходит в форму $Д_{Р 3 \Pi \text {. }}$

Из начисленной заработной платы в настоящее время, начиная с 2001 г., удерживается единый фиксированный налог на доходы физических лиц (НДФЛ) по ставке $13 \%{ }^{1}$. Оставшаяся часть заработной платы обычно называется располагаемой заработной платой (доходом). Располагаемая заработная плата как доход физических лиц в современной макроэкономике традиционно делится на потребление $(C)$ и сбережения $(S)$, или $Д_{P з \Pi}=C+S$.

Начисление заработной платы осуществляется по Марксу и подтверждается практикой постсоветского периода на основе двух ее форм: а) повременной и б) поштучной (сдельной), которые в советский период входили в «жесткую» тарифную систему оплаты труда. Эта «жесткость» сохраняется в настоящее время прежде всего для лиц, работающих в бюджетной сфере. Здесь следует отметить, что «жесткость», в частности, ставок заработной платы, как показывает опыт, при определен-

\footnotetext{
Здесь следует отметить, что в поздний советский (1984-1991 гг.) и переходный (1992-2000 гг.) периоды использовалась прогрессивная шкала подоходного налога лиц наемного труда.
}

ных условиях может выражаться в двух эффектах. Первый - связан с возникновением вынужденной безработицы по Кейнсу в условиях капитализма [4, с. 22-24], второй - возник при социализме в советский период и связан с образованием дефицичта низкоквалифицированной рабочей силы.

Четвертая стадия. $Д_{P C з \Pi}-T_{C \Pi T}$. Расходование денежной заработной платы $Д_{Р С з п}$ связанно с потребительским выбором или, другими словами, с формированием «потребительской корзины». В практическом плане этот выбор не представляет, на наш взгляд, сущзественной научной проблемы, поскольку он доступен любому нормальному покупателю, обладающему так называемым «здравым смыслом». Поэтому, вероятно, К. Маркс оставил его вне «Капитала». Однако в литературе мейнстрима этому выбору, напротив, придается существенное значение, поскольку потребителю отводится роль начальной и последней «инстанции рыночного механизма», действующего на основе потребительского спроса [5]. По этому поводу отметим следующее. Так называемые бюджетные линии, кривые безразличия, предельные нормы замещения и др. инструменты маржинального анализа потребительского выбора, несмотря на их «элегантный характер», не поддаются опытной верификации. Поскольку в практическом выборе важно не «безразличие», а, наоборот, «различие», связанное с дифференциацией товаров и торговой маркой изделий.

Пятая стадия. ....П.. Процесс потребления средств потребления с целью удовлетворения потребностей и производством (воспроизводством) рабочей силы.

В переходный период в связи с приватизацией многие наемные работники стали частными собственниками квартир, ведомственного жилья и других подобных средств потребления длительного пользования. По аналогии с классическим и марксистским делением производительного и торгового капитала на а) основной и б) оборотный в настоящее время потребительские фонды (капитал), на наш взгляд, также можно подразделить на 1) основные и 2) оборотные потребительские фонды (капитал).

Основные потребительские фонды - это жилье, домашнее оборудование, соответствующая инфраструктура и другие элементы, которые по частям, по мере их износа необходимо переносить на стоимость товара рабочая сила. Их возмещение должно осуществляться за счет указанных выше сбережений.

Оборотные потребительские фонды (капитал) - это предметы питания, одежды, обуви, т.е. предметы потребления, служащие менее одного года, их возмещение должно происходить за счет текущего потребления, вхо- 
дящего в один оборот, или кругооборот, стоимости товара рабочая сила.

В этой связи теория предельной полезности, определяющая, в частности, пределы потребления, имеет свое опытное подтверждение в постсоветский период, поскольку связана с ограничением объемов потребительского спроса и образованием минимальных потребительских запасов для поддержания непрерывности процесса потребления.

Шестая стадия. $Y_{\Pi}-T_{B P C}$. Состояние удовлетворенности и воспроизводство рабочей силы как товара. В рассматриваемую стадию входит досуг, воспитание детей, полноценный отдых в период отпусков и др. В этой связи маржинальный анализ выбора между «досугом» и «трудом» для наемного работника невозможно верифицировать в массовом масштабе, поскольку для наемного работника, лишенного средств производства и наличия значительных сбережений, нет указанного выбора, а есть довольно «жесткая» необходимость вновь и вновь продавать свою рабочую силу.

В кратко рассмотренные стадии процесса кругооборота товарной формы рабочей силы входят также в кругообороты а) денежной формы кругооборота стоимости рабочей силы,

$$
\begin{aligned}
& Д_{P C 3 \Pi}-T_{C \Pi T} \ldots \Pi_{T} \ldots V_{\Pi}-T_{B P C} \ldots T_{P C}-Д_{3 \Pi \ldots} \ldots T_{P} . . \\
& P-Д_{Р 3 \Pi \ldots} \ldots Д_{P C 3 \Pi}(5)
\end{aligned}
$$

и б) потребительской формы кругооборота стоимости рабочей силы,

$$
\begin{aligned}
& \ldots \Pi_{T} \ldots V_{\Pi}-T_{B P C} \ldots T_{P C}-Д_{3 \Pi} \ldots T_{P} \ldots P-Д_{P 3 \Pi \ldots} \\
& Д_{Р С 3 \Pi}-T_{C П T T} \ldots \Pi T \ldots
\end{aligned}
$$

Рассмотрим их подробнее.

4. Как видно из модели 5, воспроизводство рабочей силы начинается и заканчивается денежной формой заработной платы, которая имеет характер потока денежных расходов.

В этой форме, во-первых, у наемных работников в краткосрочном периоде одного оборота может возникнуть так называемая «денежная иллюзия».

Во-вторых, именно в этой форме возникает деление заработной платы по стоимости на а) номинальную и б) реальную, которая отрицает указанную «денежную иллюзию».

B-третьих, из понимания взаимной связи денежных расходов и уровня цен на потребительские товары вытекает двойная эмпирическая закономерность.
Первая. При данной величине денежных расходов в краткосрочном периоде одного оборота уровень потребления наемных работников зависит от уровня цен на потребительские товары.

Вторая. Если уровень цен на потребительские товары дан, то уровень потребления наемных работников зависит от величины расходов денежной заработной платы.

В модели 6, круговое воспроизводство рабочей силы начинается и заканчивается процессом потребления. Если присмотреться к данной модели, то можно отметить следующее.

В целом данная фигура подчеркивает непрерывность процесса потребления. С позиции непрерывности процесса потребления, по аналогии с категорией «воспроизводство», можно сформулировать категорию «воспотребления», означающую непрерывность и возобновляемость процесса потребления для поддержания жизни наемных работников.

В эту фигуру в качестве скрытых, но существенных моментов, входит а) процесс профессионального обучения, доведения пассивной рабочей силы до ее активного состояния; б) выход наемных работников на заслуженный отдых, т.е. пенсию; и в) простое и расширенное воспроизводство рабочей силы, связанное с рождением и воспитанием детей, новой рабочей силы.

По-видимому, именно на основе этой фигуры можно вслед за Марксом утверждать, что, например, денежная заработная плата сводится к стоимости товара рабочая сила, а стоимость товара рабочая сила сводится в конечном счете к стоимости потребляемых жизненных средств, включая моральный, исторические и др. институциональные аспекты.

\section{Зак^ючение}

В результате проведенного исследования можно сделать следующие выводы.

Во-первых, теоретическая модель кругооборота товарной формы рабочей силы, выведенная на основе критического анализа кругооборота капитала, рассмотренного и изложенного во втором томе «Капитала» К. Маркса, подтверждается (верифицируется) данными опыта постсоветского периода.

Во-вторых, при конструктивно-критической верификации указанной модели оказалось, что эту модель можно рассматривать как наиболее общую, в которую можно включить многие соответствующие проблема- 
тике воспроизводства рабочей силы подходы, модели мейнстрима и маржинализма.

В-третьих, кругооборот товарной формы рабочей силы на стадиях «внешнего рынка труда» и «внутреннего рынка труда» сопрягается с кругооборотом капитала. Это означает, что воспроизводство рабочей силы в целом, несмотря на свой особенный кругооборот, нельзя абсолютизировать, т.е. необходимо видеть единство интересов как рабочих, так и работодателей, что является экономической основой концепции социального партнерства «труда» и «капитала», включая, разумеется, двусторонний кон- троль как со стороны профсоюзов, так и работодателей.

В-четвертых, проведенная верификация позволила выделить фигуры а) денежной и б) потребительской формы кругооборота стоимости рабочей силы. В частности, воспроизводство рабочей силы с позиции стадии воспотребления, отраженной в формуле 6, позволяет выйти на формулировку нового третьего, наряду с первылм и вторым по Марксу, подразделения общественного воспроизводства, связанного с «производством людей посредством людей» на основе потребления средств потребления, досуга, рождения, воспитания новой рабочей силы.

\section{ЛИТЕРАТУРА}

1. Маркс К. Капитал: критика политической экономии. Том II: [пер. с нем., фр., англ.] / Карл Маркс: [предисл. Л. Л. Васиной, В.С. Афанасьева; послесл. В. И. Маевского]. - дораб. - М.: Эксмо, $2012-1200$ с.

2. МарксК. Капитал: критика политическойэкономии. Т.І.:[пер.с снем., фр., англ.]/Карл Маркс; [введ. О. И. Ананьина; пред.Л. Л. Васиной, В. С. Афанасьева]. М.: Эксм0, 2012.- $1200 \mathrm{c}$.

3. Мизес Л. Человеческая деятельность: трактат по экономической теории / Людвиг фон Мизес; пред. с 3-го испр. англ. изд. А. В. Куряева. — Челябинск: Социум, 2012.- 878 c.

4. Кейнс Дж. М. Общая теория занятости, процента и денег.- М.: Гелиос АРВ, 1999. — 352 с.

5. Теория потребительского поведения и спроса (серия «Вехи экономической мысли» Вып. I) / под ред. В. М. Гальперина.- СПб.: Экономическая школа, 1993. - 380 c.

(с) Крышка Виктор Иванович ( kryshka@mail.ru).

Журнал «Современная наука: актуальные проблемы теории и практики»

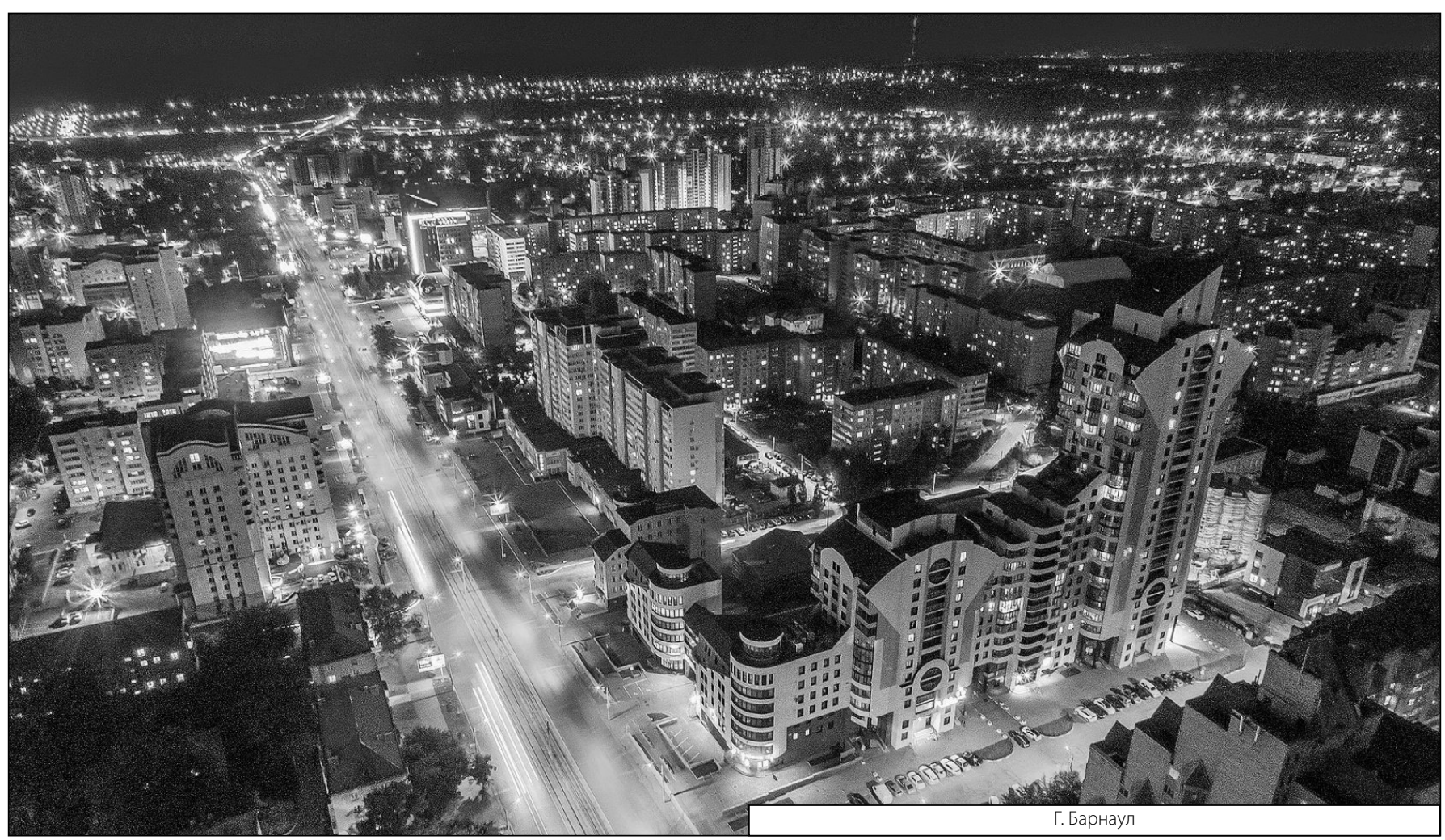

